\title{
Fortalezas y debilidades de la constitución española, 40 años después
}

\author{
Strengths and weaknesses of the spanish constitution, 40 \\ years later
}

Nuria Belloso Martín ${ }^{1}$

\section{Resumen:}

La Constitución española, aprobada en referéndum el 6 de diciembre de 1978, acaba de cumplir cuarenta años. Esta efemérides ha sido un momento propicio para volver la vista atrás y reflexionar sobre la andadura de nuestra Carta Magna. Pero también para pensar en los retos futuros a los que deberá de hacer frente. En este estudio se ponen de manifiesto algunas de las debilidades que el texto constitucional presenta, como también las fortalezas que han permitido sostener a la Norma fundamental de nuestro ordenamiento jurídico. Los derechos y libertades fundamentales, enunciados en un amplio catálogo y, principalmente, con un sólido sistema de garantías, es uno de los mayores logros de la Carta Magna. Como cualquier obra humana, es perfectible, y a ello deben ir ahora los esfuerzos, madurando las reformas que convenga realizar.

Palabras llave: Constitución española, fortalezas, debilidades, reformas.

\begin{abstract}
:
The Spanish Constitution, approved by referendum on 6 December 1978, has just turned forty years old. This anniversary has been a propitious moment to look back and reflect on the progress of our Magna Carta. But also to think about the future challenges it will have to face. This study highlights some of the weaknesses that the constitutional text presents, as well as the strengths that have made it possible to sustain the fundamental norm of our legal system. Fundamental rights and freedoms, enunciated in a broad catalogue and, mainly, with a solid system of guarantees, is one of the greatest achievements of the Magna Carta. Like any human work, it is perfectible, and that is where the efforts must now go, maturing the reforms that need to be carried out.
\end{abstract}

Key words: Spanish Constitution, strengths, weaknesses, reforms.

\footnotetext{
${ }^{1}$ Nuria Belloso Martín es Catedrática de Filosofía del Derecho en la Universidad de Burgos (España). Mediadora Civil y Mercantil. Directora del Departamento de Derecho Público. Directora del Curso de Especialista en Mediación Familiar. Directora del Curso de Mediación Civil, y Mercantil." Miembro del Grupo de Pesquisa: "Observatório de Politicas Públicas, Direito e Proteção Social" de la Universidade Estacio de Sá -UNESA-(Brasil). El presente trabajo se inscribe en el marco del Proyecto de Investigación "Fundamentos teóricos del constitucionalismo: un modelo jurídico para la sociedad global" - Convocatoria 2016- Proyectos I + D. Código: DER2016-76392-P.
} 


\section{INTRODUCCIÓN}

El día 6 de diciembre de 1978 es una fiesta para celebrar y conmemorar la efemérides de una Constitución que ha permanecido vigente durante 40 años, la Constitución española. También los aniversarios constituyen un momento propicio para realizar unas reflexiones sobre el texto de la Carta Magna. ${ }^{2}$ Ese es el objetivo del presente estudio.

La influencia de las Constituciones españolas en Iberoamérica data de la de 1812, Constitución que, en su artículo 1º, establecía: "La Nación española es la reunión de todos los españoles de ambos hemisferios". La Constitución de Cádiz tuvo un importante impacto sobre las colonias españolas en América y sobre el constitucionalismo de los nuevos países hispanoamericanos,

La Constitución de 1978 ha sido modelo y fuente de inspiración a varias de las Constituciones iberoamericanas. Por ejemplo, la Constitución de la República de Brasil, de 1988, tomó como modelo a la Constitución portuguesa de 1976 y a la española de 1978. Junto a la influencia de la Carta Magna como tal, hay que subrayar que el proceso democrático español influyó en la propia democratización de numerosas naciones hermanas de Iberoamérica.

La denominada corriente del nuevo constitucionalismo latinoamericano (Bolivia, Ecuador) viene a añadir algunos elementos novedosos a los textos constitucionales (derecho de la Naturaleza, plurinacionalidad) pero el sustrato básico en el que se apoyan sigue siendo el de nuestro constitucionalismo. De ahí la relevancia de conocer lo que la Carta Magna española de 1978 ha aportado y ha supuesto.

En la exposición utilizaremos el sistema DAFO, apropiado para poder realizar balance de situaciones, periodos o actividades realizadas o también de propuestas a desarrollar. Contrasta las Fortalezas/ Debilidades por un lado, y, por otro, Oportunidades/ Amenazas. En la exposición que voy a realizar voy a utilizar únicamente la comparativa de Fortalezas y Debilidades. Voy a empezar por dos Debilidades. Después me referiré a dos Fortalezas. Y, por último, ofreceré unas reflexiones finales principalmente referidas al tema sobre el que más se está hablando con ocasión de este aniversario, como es el de la conveniencia o necesidad de llevar a cabo una reforma de la Carta Magna. Asimismo, voy a utilizar como hilo conductor de mi exposición el principio de igualdad (art.14 CE) es decir: si todos somos iguales ante la ley.

\footnotetext{
${ }^{2}$ Los aniversarios señalados tales como los 20 años, los 25 años o los 30 años de la aprobación de la carta Magna, han sido una excelente ocasión para hacer balance sobre la misma. Vid. PECESBARBA, G., "La Constitución Española ayer y hoy", Gabriel Cisneros Laborda, Miguel Herrero y Rodríguez de Miñón (Coordinadores) 20 años después: la constitución cara al siglo XXI, 1998, pp. 93-126; y del mismo autor, "25 años de la Constitución: entrevista a Gregorio Peces-Barba Martínez". José Félix Tezanos Tortajada (entrev.), Temas para el debate, №. 100 (marzo), 2003 (Ejemplar dedicado a: 25 años de la Constitución), pp. 21-32; "La reforma de la constitución", Claves de razón práctica, $\mathrm{n}^{\circ}$ 148, 2004, pp. 26-31; Las funciones de la Constitución”, en Alfonso de Julios Campuzano (Coordinador) Ciudadanía y derecho en la era de la globalización, Madrid, Dykinson, 2007, pp. 41-60.
} 


\section{Significado de una Constitución}

Ubi societas, ibi ius. Es un adagio romano que significa que, donde hay sociedad, hay derecho. Y ello, porque en cualquier tipo de organización social surgen conflictos. Y para evitar que los conflictos se resuelvan por la fuerza -por quien siempre tiene más fuerza-, para evitar desigualdades-, los integrantes de las comunidades deciden darse unas leyes, por las que regirse.

Y ahora bien, los lectores podrán pensar, qué tiene que ver esto con la Constitución. Porque el quid de la cuestión radica en quién decide las normas. Y aquí surge la idea de democracia. Democracia significa que el poder reside en los individuos, no en unos pocos, ni en los que tengan poder o en los elegidos por Dios, sino en todos los individuos. Hacer elecciones, votar, es la manera en cómo se decide organizarse y qué decisiones tomar. Simplificando, la Constitución es el acuerdo de mínimos entre todos los individuos de un pueblo: cuáles son los símbolos del país (bandera, himno, lengua), qué sistema de gobierno adopta (república, monarquía) qué derechos tienen sus ciudadanos, cómo se organizan los Poderes, etc.

Para hacer una Constitución es necesario convocar una asamblea constituyente, que es el conjunto de personas que representa al pueblo y que se reúnen para escribir la Constitución. Una vez que la asamblea redacta la constitución, esta tiene que ser aprobada por todo el pueblo, y para ello se lleva a cabo un referéndum. Bajo el Gobierno del Presidente Adolfo Suárez, se celebraron las primeras elecciones democráticas el 15 de junio de 1977. Las Cortes generales elegidas ese día designaron un grupo de 7 miembros en representación de los diferentes partidos -Padres de la Constitución- ${ }^{3}$ encargados de redactar el proyecto de Constitución.

La Constitución española actual entró en vigor el 29 de diciembre de 1978, después de ser aprobada en referéndum el 6 de diciembre de ese mismo año.

España ha tenido distintas Constituciones:

-La primera fue Constitución de 1812 (conocida como la Constitución de Cádiz) ${ }^{4}$, bajo la monarquía absolutista de Carlos IV;

- $\quad$ La Constitución de 1837 (Isabel I)

- La Constitución de 1855 (retroceso). La elaboraron las Cortes.

- La Constitución de 1869 (ideas revolucionarias)

- La Constitución de 1878 (vuelve el rey -Alfonso XIII-). El entonces presidente del Gobierno, Antonio Cánovas del Castillo, convoca una asamblea constituyente de seiscientas personas, que incluía a todos aquellos que habían participado en la política española en los últimos treinta años, al objeto de obtener el mayor consenso. Esta Constitución estuvo en vigor 53 años (periodo más largo de la historia constitucional española).

- $\quad$ La Constitución de la república, de 1931.

Pero no duró. En 1936 se produce el golpe de Estado por parte del ejército contra la república, a la que sigue una guerra civil que dura tres

\footnotetext{
${ }^{3}$ Fueron: Gabriel Cisneros, Miguel Herrero y Rodríguez de Miñón, Pedro Pérez Llorca, Manuel Fraga, Gregorio Peces-Barba, Miquel Roca y Jordi Solé Tura.

${ }^{4}$ Entró el vigor el día de San José, es decir, el 19 de marzo. Por eso, sus partidarios la llamaron "la pepa".
} 
años. Los republicanos pierden la guerra y empieza una dictadura de cuarenta años presidida por el General Francisco Franco.

\section{2-La Constitución como instrumento que ha facilitado una transición pacífica}

Quizás la existencia misma de la Constitución parezca hoy un hecho natural, especialmente a los menores de cuarenta años que no han conocido más que nuestro sistema constitucional. Pero es necesario reconocer el enorme esfuerzo que supuso pasar de la imposición de un modelo de convivencia por una parte de la sociedad a la otra, a alcanzar, en un juego de renuncias recíprocas, el más amplio denominador común.

Explicar lo que ha aportado la CE a los estudiantes de Derecho, tanto en su vida ordinaria como principalmente en relación a los Derechos fundamentales, ha sido uno de mis principales objetivos. Que al cumplir los 18 años de edad se alcance la mayoría de edad, lo determina la CE (art.12); la posibilidad de contraer matrimonio y sus efectos, lo establece también el texto constitucional (art.32); ${ }^{5}$ estudiar es posible gracias a la CE (art.27), donde dice que todos tenemos derecho a la educación, además de señalar que la educación es obligatoria y gratuita; el poder reunirnos a celebrar una fiesta es posible gracias al art. $21 \mathrm{CE}$, el "derecho de reunión" (diferencia una dictadura de una democracia). Es decir, la Constitución tiene una influencia decisiva en numerosos aspectos de nuestra vida cotidiana, de los que no solemos ser conscientes. ${ }^{6}$

La Constitución española tiene 169 artículos en total. Y los artículos se dividen en tres partes: a) Un preámbulo y un Título Preliminar; b) Una Parte Dogmática -Título I- con los Derechos y Libertades; c) Una parte orgánica, en la que se trata la división de poderes.

La Constitución de 1978, con sus 40 años de recorrido, ha logrado encauzar el mayor periodo democrático y de bienestar de toda nuestra historia. Una transición basada en el consenso de todas las fuerzas políticas y sociales permitió dejar atrás 40 años de dictadura -a pesar del intento de ruptura el 23 de febrero de 1981, con el intento fallido de golpe de estado en el Congreso de los Diputados por parte del Teniente Coronel Tejero -. Sólo se ha declarado el estado de alarma en una ocasión a lo largo de estos cuarenta años ${ }^{7}$ Las últimas décadas han permitido consolidar un estado social y democrático de derecho, con un nivel de bienestar comparable a los países de nuestro entorno. Todo ello ha corrido en paralelo, además, con la fructífera integración en la Unión Europea desde 1986, la recuperación del papel internacional

\footnotetext{
${ }^{5}$ Hasta el 3 de julio de 2005, sólo podían casarse personas de distinto sexo. A partir de la entrada en vigor de la LEY 13/2005, de 1 de julio, por la que se modifica el Código Civil en materia de derecho a contraer matrimonio, es posible que las personas del mismo sexo contraigan matrimonio. (En 2012, el Tribunal Constitucional avaló que la CE lo permitía, aunque no lo dijera de forma explícita. Lo justificó recurriendo a una interpretación "evolutiva" del texto constitucional).

6 PÉREZ ROYO, J., La Constitución explicada a mis nietas. Las claves para conocer nuestros derechos y ser más libres, Barcelona, Penguim Random House Grupo Editorial, 2018.

7 España declaró el estado de alarma por primera vez en la historia de la democracia el 04 de diciembre de 2010. El caos aeroportuario originado por el plante masivo de los controladores (los

encargados de ordenar la circulación aérea) llevó al Gobierno a decretarlo a la vista de que los vigilantes del aire no deponían su actitud. A partir de su publicación en el BOE, los controladores quedaron "movilizados" y bajo las órdenes de la autoridad militar. A partir de ese momento fueron requeridos de uno en uno, a través de burofax, para que acudieran a trabajar. "Si no acuden a sus puestos de trabajo pasan a incurrir en un delito de desobediencia", castigado con penas de prisión.
} 
que corresponde a nuestro país, y la internacionalización de nuestra economía. En definitiva, con esta Constitución hemos disfrutado de un periodo de progreso sin precedentes.

La Constitución, como es sabido, constituye a España en un Estado social y democrático de Derecho cuya forma política es la Monarquía Parlamentaria, ${ }^{8}$ proclama y asegura nuestros derechos fundamentales, diseña un marco democrático de actuación de los poderes públicos, y garantiza el derecho a la autonomía de las nacionalidades y regiones y la solidaridad entre ellas dentro de la unidad indisoluble de la Nación española, que es el fundamento de la Constitución misma.

$\mathrm{Y}$ es que la existencia y suerte de la democracia está vinculada a la existencia de una Constitución normativa, la condición que hace de la multitud, un pueblo y de los súbditos, ciudadanos; sin esa condición de norma de Derecho falta, en suma, la sujeción del poder a normas y como fruto necesario de esa sujeción un espacio en el que el individuo puede encontrar y ejercer la libertad y participar, como dice nuestra Constitución, «en los asuntos públicos» y «acceder en condiciones de igualdad a las funciones y cargos públicos» (art. 23.1 y 2).

La Constitución normativa significa el sometimiento de todos a una Ley primera y superior, incontestable; asegura la soberanía de la Nación y la dignidad de su sometimiento al Derecho. La defensa de la supremacía normativa incondicionada de la Constitución se confía al sistema de justicia constitucional en el que tiene un papel propio y supremo el Tribunal Constitucional (Título IX de la Constitución).

El artículo 93 de la Constitución (la llamada «cláusula europea del ordenamiento español» de la que la Declaración del Tribunal Constitucional 1/2004, de 13 de diciembre, ha subrayado su «sustancia integracionista») ${ }^{9}$ ha permitido nuestra integración, a través de la cesión del ejercicio de competencias derivadas de la Constitución, en la hoy Unión Europea (moneda, política económica ycrecientemente, aun sin llegar al máximo nivel de integración- la justicia y la política exterior y de defensa).

Título III. De las Cortes Generales

Capítulo tercero. De los Tratados Internacionales

\section{Artículo 93}

Mediante la ley orgánica se podrá autorizar la celebración de tratados por los que se atribuya a una organización o institución internacional el ejercicio de competencias derivadas de la Constitución. Corresponde a las Cortes Generales o al Gobierno, según los casos, la garantía del cumplimiento de estos tratados y de las resoluciones emanadas de los organismos internacionales o supranacionales titulares de la cesión.

\footnotetext{
${ }^{8}$ Nuestra forma de Gobierno es una monarquía parlamentaria, en la que el rey ejerce las funciones de jefe de Estado (que es quien representa al país en determinados actos) pero no toma decisiones sino que obedece a los poderes legislativo y ejecutivo. Se dice que en las monarquías parlamentarias, los reyes "reinan, pero no gobiernan", es decir, representan el país pero no lo dirigen. En Europa hay diversas monarquías parlamentarias (Reino Unido, Bélgica, Holanda, Suecia, Noruega o Dinamarca). ${ }^{9}$ El Tribunal pudo precisar la relación entre la Constitución y el Derecho de la Unión Europea, estableciendo que la primacía del Derecho europeo no contradecía la supremacía constitucional, ya que ésta versaba sobre relaciones de jerarquía normativa, y aquélla sobre supuestos de prioridad en la aplicación de las normas. El interrogante es el de hasta dónde puede llegarla flexibilización de la "apertura constitucional" sin poner en peligro la misma esencia de la Constitución.
} 
Tras esta introducción, vamos a referirnos a dos debilidades de nuestra Constitución y dos fortalezas, entre otras.

\section{A- DEBILIDADES}

\section{Primera Debilidad: las vulneraciones del principio de igualdad derivadas del modelo territorial (organización del modelo territorial)}

Frente al Estado centralizado del franquismo, y en virtud de la histórica conflictividad territorial de nuestro país, el constituyente no estableció una estructura, sino un marco para desarrollar un proceso de descentralización. Así, los artículos 2, 137 y todo el Titulo VIII, así como algunas disposiciones adicionales y transitorias marcaban las vías para la autonomía y la solidaridad dentro de la unidad de España.

La Carta Magna, en el Título VIII de la Constitución, configuró el llamado "Estado de las Autonomías" 10 integrado por diecisiete Comunidades Autónomas en las que se incluyen dos ciudades autónomas (Ceuta y Melilla) y una Comunidad foral. Durante la Segunda República, las que habían tenido más protagonismo habían sido las Comunidades Vasca y la Comunidad Foral de Navarra. Se alegó la identidad cultural y la diferenciación histórica para diseñar su régimen especial. ${ }^{11}$ Bien sea por razones fiscales o nacionalistas, cada vez tiene mayor relevancia en el status de ciudadano "en qué lugar haya nacido".

País Vasco y Navarra son las dos Comunidades Autónomas que cuentan con más recursos para ofrecer servicios públicos a sus ciudadanos. El funcionamiento del concierto económico explica que exista esta asimetría en el sistema fiscal. La Agencia Tributaria del País Vasco recauda todos los impuestos, incluidos los estatales, tiene una amplia capacidad normativa sobre ellos y anualmente dan al Estado una parte de la recaudación, el llamado "Cupo", ${ }^{2}$ por los servicios que éste presta en sus territorios, que se valoran de común acuerdo entre cada una de estas

\footnotetext{
${ }^{10}$ Vid. AA.VV., Historia, nación y nacionalismo español, Madrid, Galaxia Gutenberg, Fundación Ortega y Gasset, 2013.

${ }^{11}$ Disposición Adicional Primera de la Constitución española: "La Constitución ampara y respeta los derechos históricos de los territorios forales. La actualización general de dicho régimen foral se llevará a cabo, en su caso, en el marco de la Constitución y de los Estatutos de Autonomía". Aquí radica una de las limitaciones históricas que la Constitución del 78 debería de haber evitado. Si se partía desde cero, para elaborar una Constitución, el reconocimiento de derechos históricos sólo se hizo para determinadas Comunidades. El punto de partida era pues, desigual.

${ }^{12}$ País Vasco y Navarra recaudan casi todos los impuestos y, de este dinero, dan una parte al Estado por las competencias no transferidas y también realizan una pequeña aportación al fondo de compensación entre comunidades autónomas. Este sistema les beneficia al tener una renta relativamente alta. Es decir, existe una gran diferencia entre comunidades autonómicas sobre la financiación que recibe cada uno de sus habitantes. Vid. la gráfica "Financiación regional para competencias homogéneas e igual esfuerzo fiscal en 2013". Fuente: <https://www.elblogsalmon.com/economia-domestica/el-cupo-vasco-es-realmente-injusto-con-elresto-de-comunidades $>$.

Partido Popular -PP- y Partido Nacionalista Vasco -PNV- han pactado, a finales de 2017, que el Estado devuelva al Gobierno vasco 1.400 millones de euros que se entienden cobrados de más, un dinero que se irá descontando de forma progresiva durante los próximos cinco años del citado Cupo: el 10\% de los 1.400 millones se descontará del pago de este año, el $15 \%$ el año próximo, el $20 \%$ al siguiente, un $25 \%$ en el cuarto ejercicio y el 30\% restante, en el último año. el gobierno del PP compensará al País Vasco no solo ha incluido una rebaja del cupo y la devolución de los 1.400 millones de euros indicados sino una inversión de 3.380 millones de euros hasta el año 2023 para infraestructuras ferroviarias que conectaran las 3 capitales vascas, y así hasta 36 acuerdos.
} 
Comunidades y el Gobierno central. Es decir, el Cupo es el dinero que el País Vasco paga al Estado por las competencias no transferidas. ${ }^{13}$

Título VIII. De la Organización Territorial del Estado

\section{Capítulo primero. Principios generales}

\section{$\underline{\text { Artículo } 139}$}

\section{Todos los españoles tienen los mismos derechos y obligaciones en cualquier parte del territorio del Estado.}

La igualdad entre todos los ciudadanos españoles no es una realidad. Sobre el principio de igualdad se han escrito miles de páginas, estudiando las múltiples vertientes que presenta. Su triple naturaleza jurídica como valor superior del ordenamiento jurídico, como principio jurídico y como derecho fundamental, ha propugnado estudios desde enfoques muy diversos.

El artículo 14 de la Constitución española -CE- establece un derecho de igualdad general ("Todos son iguales ante la ley") y unas prohibiciones específicas de discriminación, es decir, una enumeración, no cerrada, de prohibición de discriminaciones “ “... sin que pueda prevalecer discriminación alguna por razón de nacimiento, raza, sexo, ${ }^{14}$ religión, opinión, o cualquier otra circunstancia personal o social".

Nos referimos aquí a la igualdad que deriva del Estado de las Autonomías. El sistema de financiación de las Comunidades Autónomas ha traspasado el ámbito meramente fiscal o económico y se ha convertido en una causa bellum entre las Autonomías, a cuenta de las desigualdades que se acaban proyectando entre los ciudadanos. Diferentes niveles de financiación, distinta dotación en infraestructuras, desigual calidad en los servicios públicos. Basta hacer un repaso de los distintos

${ }^{13}$ El País Vasco durante el año 2013 obtuvo una financiación equivalente a 4.170 euros por habitante, una cifra que duplica los 2.030 euros de media que recibieron las Comunidades Autónomas de régimen común. La segunda Comunidad Autónoma con mayor financiación por habitantes es Navarra, con 3.266 euros por habitante.

\footnotetext{
${ }^{14}$ No podemos detenernos ahora en un análisis de la igualdad entre hombre y mujer, pero sí convienen reseñar que la ideología de género, junto a algunas virtudes, si se lleva a una única perspectiva, produce una discriminación con respecto al hombre. Afirmaciones como que la palabra de una mujer tienen presunción de veracidad frente a la de un hombre, acaban minando los fundamentos jurídicos (valor de la prueba, igualdad, etc.). Por ejemplo: "El Supremo sentencia que en una agresión mutua el hombre siempre ejerce violencia de género sobre la mujer. El Alto Tribunal considera que "no es preciso acreditar una específica intención machista debido a que cuando el hombre agrede a la mujer ya es por sí mismo un acto de violencia de género con connotaciones de poder y machismo". El Supremo recalca que los actos de violencia que ejerce el hombre sobre la mujer en una relación afectiva de pareja constituyen "actos de poder y superioridad con independencia de cuál sea la motivación o la intencionalidad" y constituyen un delito de violencia de género. "Con este fallo, el Supremo revoca una sentencia de la Audiencia Provincial de Zaragoza que, tras una agresión mutua, absolvió a una pareja del delito de maltrato y considera así que "no es preciso acreditar una específica intención machista debido a que cuando el hombre agrede a la mujer ya es por sí mismo un acto de violencia de género con connotaciones de poder y machismo". La sentencia, en la que ha sido ponente el magistrado Vicente Magro Servet, un reconocido magistrado feminista, diferencia entre el delito de violencia de género contra una mujer y el de violencia familiar o doméstica. "Probada la agresión, el hecho es constitutivo de violencia de género y si hay agresión mutua, como en este caso, ambos deben ser condenados. Por violencia de género al hombre, y familiar a la mujer", señala. Diario Público, 09.01.2019. 〈https://www.publico.es/sociedad/violencia-generosupremo-sentencia-agresion-mutua-hombre-siempre-ejerce-violencia-machista-mujer.html.>.
} 
indicadores autonómicos para que se ponga de manifiesto esa desigualdad. ${ }^{15}$ Conviene recordar que el concepto de igualdad es puramente relacional: a) Cualquier planteamiento que se haga con respecto al interrogante de si A" es igual, nos obliga a buscar a un sujeto o un colectivo "B", es decir, la igualdad nos lleva a compararlo con alguien.

Atribuimos tanto a una equivocada aplicación de los principios de fiscalidad de la Carta Magna (artículo $31 \mathrm{CE})^{16}$ como al Estado de las Autonomías la mayor parte de responsabilidad del resultado claramente desigual desde el ámbito tanto de financiación -qué reciben los ciudadanos- como en la fiscalidad -cómo contribuyen los ciudadanos- ${ }^{17}$. La igualdad no sólo se predica con respecto a qué esperamos que la sociedad como un todo nos distribuya (servicios sociales, sanidad, educación, financiación de la Comunidad Autónoma en la que residimos) -justicia general o legal- sino también, en relación a cómo contribuimos cada uno de los ciudadanos con respecto a la sociedad en su conjunto (impuestos estatales e impuestos de carácter autonómico) -justicia distributiva-.

Título I. De los derechos y deberes fundamentales

Capítulo segundo. Derechos y libertades

Sección 2. ${ }^{\mathrm{a}}$ De los derechos y deberes de los ciudadanos

\section{$\underline{\text { Artículo 31 }}$}

1. Todos contribuirán al sostenimiento de los gastos públicos de acuerdo con su capacidad económica mediante un sistema tributario justo inspirado en los principios de igualdad y progresividad que, en ningún caso, tendrá alcance confiscatorio.

2. El gasto público realizará una asignación equitativa de los recursos públicos, y su programación y ejecución responderán a los criterios de eficiencia y economía.

3. Sólo podrán establecerse prestaciones personales o patrimoniales de carácter público con arreglo a la ley.

El Estado de las Autonomías y la delegación de competencias en áreas como la sanidad, la educación y los servicios sociales (política pública de vivienda, pobreza energética o renta mínima ciudadana), ha dado lugar a que, como reciben distintas aportaciones del Gobierno central, ${ }^{18}$ las prestaciones que reciben los ciudadanos

\footnotetext{
15 Por ejemplo, en gasto sanitario por habitante, el País Vasco es la autonomía que más invierte (más de 1.600 euros según datos del 2015), hasta el punto de superar en un $60 \%$ a la que menos dinero destina: Andalucía (1.090 euros por habitante). Y una distancia similar se aprecia en el gasto público por alumno en enseñanzas no universitarias. Mientras el País Vasco gasta casi 9.000 euros por alumno, la media española se sitúa en poco más de 5.000. CASTRO, C., “Es tan real como se dice la igualdad entre españoles?” Diario La Vanguardia, 17/09/2017. <https://www.lavanguardia.com/politica/20170917/431347759665/desigualdad-economica-espanacomunidades-autonomas-pib-espanol-diferencias-financiacion-infraestructuras.html>.

${ }^{16} \mathrm{El}$ artículo 31 de la CE establece en sus tres apartados una serie de principios que marcan las condiciones para cumplir con los deberes tributarios: en el apartado primero, los principios de universalidad, individualidad, igualdad y progresividad, no confiscatoriedad y capacidad económica. En el segundo, el principio de eficacia y economía en la ejecución del gasto. En el tercero, el principio de reserva de ley en materia tributaria.

${ }^{17} \mathrm{La}$ perspectiva de nuestro estudio no se realiza desde el ámbito del Derecho Administrativo ni desde el Derecho Constitucional, sino desde el de la Filosofía del Derecho.

${ }^{18}$ El modelo vigente se estableció mediante la Ley Orgánica 8/1980, de 22 de septiembre, de Financiación de las Comunidades Autónomas (LOFCA) reformada por la Ley 22/2009, de 18 de diciembre, por la que se regula el sistema de financiación de las Comunidades Autónomas de régimen común y Ciudades con Estatuto de
} 
españoles sean también claramente diferentes. Hay diferencias entre los ciudadanos en cuanto a los servicios sociales de que disfrutan, lo cual, en un Estado de bienestar, implica una vulneración del principio de igualdad. ${ }^{19} \mathrm{El}$ principio de igualdad de oportunidades queda condicionado no por el mérito y el trabajo, sino por el lugar en el que se reside.

Recordemos que la Constitución, en su artículo 14, establece que todos somos iguales ante la ley. Y en el artículo 31 precisa además que los impuestos deben ser justos, equitativos y no deben tener afán recaudatorio. Sin embargo, un andaluz antes de recibir la herencia debe pagar a Hacienda un impuesto de sucesiones equivalente al $17 \%$ del patrimonio a heredar, mientras que un canario en las mismas circunstancias no pagará más que el 0,017\%.

Desde un principio de justicia distributiva y de justicia general o legal, resulta imperativo reclamar reformas de carácter administrativo y fiscal, que faciliten la armonización fiscal entre las distintas Comunidades Autónomas, para evitar las diferencias en el pago de algunos impuestos, en función de la Comunidad Autónoma en la que se tribute; asimismo, el Gobierno central, puesto que debe respetar el Cupo vasco y navarro (por imperativo constitucional) deberían proceder a diseñar un sistema de financiación autonómico que paliara las desigualdades existentes, a la vez que debería reforzar el sistema de solidaridad interregional.

Además, ese modelo territorial se encuentra sometido en los últimos años a críticas y desafíos, sobre todo a partir de la Sentencia 31/2010 del Tribunal Constitucional sobre el Estatuto de Autonomía de Cataluña.

\section{Segunda Debilidad: no hay ninguna referencia a las generaciones futuras}

En el texto constitucional de 1978 no hay ninguna referencia a las Generaciones Futuras. Es decir, ni se hace mención a las mismas, ni se ha regulado una institución encargada de representar y tutelar a las mismas. Tampoco se ha establecido el deber de las generaciones actuales de tomar en consideración los

\footnotetext{
Autonomía. Como explica Cuenca, "La esencia de cualquier sistema de financiación regional se concreta en tres conceptos: necesidades de gasto, capacidad tributaria y mecanismos de nivelación. Así, las necesidades de gasto se financian con dos fuentes de recursos: la capacidad tributaria y la transferencia que complementa la primera (nivelación). Si la capacidad tributaria que se otorga a cada Comunidad autónoma no alcanza para financiar sus necesidades de gasto, recibirá una transferencia positiva. Si por el contrario la capacidad tributaria cedida excede las necesidades de gasto, la transferencia será negativa. Veamos cada uno de estos tres conceptos con más detalle". CUENCA, A., "Informe. Una nueva reforma de la financiación autonómica" en Cuadernos Manuel Jiménez Abad, n¹3, Fundación Manuel Jiménez Abad de Estudios Parlamentarios y del Estado Autonómico, junio 2017, p.69. Disponible en: $<$ http://www.fundacionmgimenezabad.es/index.php?option=com_content\&view=category\&layout=blog\&id=30 2\&Itemid=100916>.

${ }^{19}$ El Gobierno central es el que lleva a cabo la mayor parte de la recaudación de los impuestos de los ciudadanos, recaudación que, después, distribuye con criterios no tan transparentes y justos como sería deseable a las Comunidades Autónomas, que son las que "generosamente" reparten en bienes y servicios (educación, sanidad, servicios sociales) entre los ciudadanos de su respectiva Comunidad. La ley Orgánica de Financiación de las Comunidades Autónomas (LOFCA), la Ley de Estabilidad Presupuestaria y Sostenibilidad Financiera, el Fondo de Liquidez Autonómico (FAL), el Fondo Social y otras legislaciones y Reales Decretos Ley que regulan los mecanismos de financiación de las Comunidades Autónomas, por parte del Ministerio de Economía, exigen un conocimiento de carácter técnico jurídico-económico que no está al alcance de todos. Los presupuestos que el Gobierno central destina a las Comunidades y entidades locales son sufragados, en un porcentaje superior al $75 \%$, por todos los ciudadanos (un $25 \%$ son impuestos autonómicos). Eso equivale a que los servicios de sanidad o de renta de inserción que recibe un andaluz pueden estar sufragados por un castellanoleonés. En definitiva, hay que dejar de esconderse en la opacidad y proceder a reformar el sistema de financiación autonómico para evitar agravios entre los españoles.
} 
intereses y necesidades de las Generaciones Futuras. Ello contrasta con la frecuente referencia a las mismas en textos internacionales y en textos constitucionales de otros países.

En la actualidad hay temas que son objeto de encendidos debates y que reconducen al concepto de Generaciones Futuras: la (in)aceptabilidad de una deuda pública, el factor de sostenibilidad para garantizar un sistema público de pensiones, las políticas energéticas, cuestiones medioambientales, política demográfica, biotecnología y biogenética, entre otras. Todos ellos desembocan en que se adoptarán decisiones que pueden acabar determinando una vida con mejores o peores condiciones para las Generaciones Futuras. En todos esos casos, en última instancia se acaba debatiendo sobre aspectos clave de la justicia entre generaciones.

\section{La categoría del tiempo futuro debería presidir cualquier toma de decisión}

Uno de los problemas que tiene la sociedad actual es la de que no ha desarrollado la capacidad de divisar más allá del momento presente. Tanto el sistema político como la cultura en general, están volcados en el presente inmediato. Las reglas de los gobiernos democráticos confieren poder durante un periodo de cuatro años, por regla general, y de nuevo hay que acudir a elecciones, donde se contrastarán los logros obtenidos en el anterior periodo de mandato.

Las generaciones venideras no tienen representantes ni en los mercados ni en la gestión política: "Las Generaciones Futuras no votan, no tienen poder político ni financiero, no pueden oponerse a nuestras decisiones".

2. Unas categorías siempre citadas y escasamente aplicadas: sustentabilidad y desarrollo sostenible

La coexistencia temporal habitual suele ser la de un mínimo de tres generaciones): la G1, la de los abuelos; la G2, la de los hijos; la G3, la de los nietos. Cada una de ellas tendrá unas problemáticas diversas (G1, sistema socio-sanitario, pensiones); G2 (mantenimiento de su empleo, contribución al sistema de pensiones, gestionar las necesidades de la G1 y de la G3); y G3 (educación, acceso al mercado de trabajo, vivienda). Se puede afirmar que se trata de problemas de "justicia espacial" pues coexisten en un mismo tiempo y los valores y los avances tecnológicos, son similares. Pero a la justicia espacial hay que sumar la justicia temporal, que resulta más dificultosa ya que las generaciones muy distantes en el tiempo, en las que no sabemos cómo estarán los avances genéticos, ni los recursos energéticos, o qué necesidades concretas tendrán.

Las cláusulas de protección general a la posteridad pueden encontrarse en diversas Constituciones, tales como:

- en el Preámbulo de la Constitución Federal de Suiza (18/04/1999): El pueblo suizo y los cantones, [...] conscientes de los logros comunes y de la responsabilidad frente a las generaciones futuras [...]".

- En el artículo 11 de la Constitución japonesa de 1947: "No se podrá impedir al pueblo el goce de ninguno de los derechos humanos fundamentales. Estos derechos humanos fundamentales, garantizados al pueblo por la Constitución, serán conferidos al pueblo de ésta y de las futuras generaciones como derechos eternos e inviolables".

- La justicia intergeneracional fiscal se ha establecido en el Art. 115 de la Constitución alemana (27/10/1994): [Límites de la toma de créditos] "La obtención de créditos y la prestación de fianzas, garantías u otras clases 
de seguridades que puedan dar lugar a gastos en ejercicios económicos futuros, necesitan una habilitación por ley federal que determine o permita el monto de los mismos".

Algunos otros textos constitucionales están sistematizados de modo tal que revelan la perspectiva generacional solamente a la luz de la interpretación, mediante normas para la protección de la cultura y de la naturaleza y, particularmente en las cláusulas relativas al patrimonio cultural. ${ }^{20}$

Generaciones Futuras y sostenibilidad se presentan como dos conceptos interrelacionados. La sostenibilidad:

“[...] el desarrollo que satisface las necesidades del presente sin comprometer la capacidad de las generaciones futuras de satisfacer sus propias necesidades-. ${ }^{21}$

${ }^{20}$ Como ejemplos, se pueden citar: a) En Italia: El párrafo $2^{\circ}$ del art. $9^{\circ}$ de la Constitución italiana, de 1947, dice: "(la República) protege el paisaje y la herencia histórica y cultural de la nación”; b) La Constitución portuguesa, de 1976, en el contexto de protección ambiental, exige garantizar la preservación de la naturaleza y la protección de los bienes culturales relativos al interés histórico o artístico. Artículo 66. Del medio ambiente y la calidad de vida: [...] 2. Para asegurar el derecho al medio ambiente, dentro del marco de un desarrollo sustentable, le corresponde al Estado, mediante organismos propios y con la implicación y la participación de los ciudadanos:[...] 3.Crear y desarrollar reservas y parques naturales y de recreo, así como clasificar y proteger paisajes y lugares, de manera a que se garantice la conservación de la naturaleza y la preservación de valores culturales de interés histórico o artístico"; c) La Constitución de Eslovenia, aprobada en 1991 y reformado en 2006, en su art. 73 dice: "Todos tienen el deber de proteger los monumentos naturales y cultural"; d) La Constitución de Estonia, aprobada en 1992 y reformado en 2007, en su art establece un Estado que garantice la conservación de la nación estonia y su cultura a través de edades; e) La Constitución de la República Checa, de 2002, promete en el preámbulo ser "fiel a todas las buenas tradiciones de las históricas del legado de los estados bajo la Corona bohemia" [...] resueltos a proteger y desarrollar su patrimonio natural, cultural, material y espiritual [...]".rarezas, y así también los monumentos culturales en armonía con la ley. El Estado y la comunidades locales cuidan la preservación del patrimonio natural y cultural"; d) La Constitución de Estonia, aprobada en 1992 y reformado en 2007, en su art establece un Estado que garantice la conservación de la nación estonia y su cultura a través de edades; e) La Constitución de la República Checa, de 2002, promete en el preámbulo ser "fiel a todas las buenas tradiciones de las históricas del legado de los estados bajo la Corona bohemia" $[\ldots]$ resueltos a proteger y desarrollar su patrimonio natural, cultural, material y espiritual $[\ldots] "$.

${ }^{21}$ El 7 de junio de 2013 se hizo público el Informe del Comité de Expertos sobre el factor de sostenibilidad del sistema público de pensiones. Los expertos recomiendan la introducción de un factor de sostenibilidad en el cálculo de las pensiones, actuales y futuras, y lo justifican por la existencia de riesgos demográficos (sociedad envejecida) y económicos (ingresos del sistema, tasa de desempleo estructural, estructura productiva, etc.) que a su juicio pondrían en peligro el sistema de pensiones. El Factor de Sostenibilidad es un mecanismo de ajuste automático de ciertos parámetros de las pensiones -edad de jubilación, años de cotización necesarios o importe inicial de la pensiónvinculado a la esperanza de vida de la población y que ya está implantado en varios países europeos. El Factor de Sostenibilidad se compone de dos fórmulas (ambas para recortar el gasto en pensiones): 1) Factor de Equidad Intergeneracional -FEI-. Actúa sólo sobre el cálculo de la pensión inicial y la modera por el aumento de la esperanza de vida respecto a un año base; Trata de proteger al sistema de pensiones de la incidencia sobre el mismo de la mayor longevidad de los futuros jubilados. El Factor de Equidad Intergeneracional (FEI) resultaría de dividir la esperanza de vida de los que han entrado en el sistema con una edad determinada en un momento anterior, entre la esperanza de vida de los nuevos jubilados que entran con la misma edad pero en un momento posterior. El resultado se multiplicaría ahora por la pensión inicial con la que los nuevos jubilados entrarían cada año en el sistema, según la normativa vigente. El objetivo es tratar de manera igual a personas que van a percibir prestaciones del sistema de pensiones durante un número de años muy distinto. El FEI utiliza 
De hecho, una de las reivindicaciones sobre la reforma del texto constitucional es la de que se incluya la revisión anual de las pensiones según la subida del IPC.

\section{Otras Debilidades}

Sin ánimo de ser exhaustivos, vamos a hacer referencia a tres de las debilidades más significativas que- a nuestro juicio- presenta la Constitución española.

\section{Excesivos aforamientos}

Quienes gozan de este fuero especial no son juzgados por el tribunal ordinario que corresponda sino que sus causas pertenecen al Tribunal Supremo.

Título III. De las Cortes Generales

Capítulo primero. De las Cámaras.

Artículo 71.3:

2.Durante el período de su mandato los Diputados y Senadores gozarán asimismo de inmunidad y sólo podrán ser detenidos en caso de flagrante delito. No podrán ser inculpados ni procesados sin la previa autorización de la Cámara respectiva.

3.En las causas contra Diputados y Senadores será competente la Sala de lo Penal del Tribunal Supremo.

Título IV. Del Gobierno y de la Administración

Artículo 102.1:

1. La responsabilidad criminal del Presidente y los demás miembros del Gobierno será exigible, en su caso, ante la Sala de lo Penal del Tribunal Supremo.

La existencia de 10.000 beneficiarios en España de este privilegio choca con países como Alemania, Reino Unido o Estados Unidos, donde no hay ninguno. Este privilegio causa suspicacias basadas en que son los parlamentarios quienes pactan la composición de estas instancias superiores, a diferencia de lo que ocurre con las salas ordinarias, más alejadas del legislativo.

Quien tiene mayor grado de protección es el rey, que no está sujeto a ningún tipo de responsabilidad. El artículo 56.3 de la Constitución le protege de cualquier investigación, incluso en su vida civil y privada. Por su parte, la reina Letizia, los

el argumento de la ganancia en esperanza de vida; 2) Factor de Revalorización Anual -FRA- utiliza básicamente el argumento de la necesidad de equilibrio entre ingresos y gastos del sistema. Determina el crecimiento anual equilibrado de las pensiones, de acuerdo con los ingresos disponibles por el sistema público de pensiones en el medio plazo. Una vez asegurado el potencial riesgo de longevidad, salvaguardaría los potenciales riesgos demográficos no asociados a la longevidad, es decir, los asociados a la tasa de dependencia, como se conoce a la ratio entre cotizantes y pensionistas. 
reyes Juan Carlos y Sofía y la princesa de Asturias son aforados ante el Tribunal Supremo.

Título II. De la Corona

$\underline{\text { Artículo } 56}$

1. El Rey es el Jefe del Estado, símbolo de su unidad y permanencia, arbitra y modera el funcionamiento regular de las instituciones, asume la más alta representación del Estado español en las relaciones internacionales, especialmente con las naciones de su comunidad histórica, y ejerce las funciones que le atribuyen expresamente la Constitución y las leyes.

2. Su título es el de Rey de España y podrá utilizar los demás que correspondan a la Corona.

3. La persona del Rey es inviolable y no está sujeta a responsabilidad.

La finalidad teórica del aforamiento es doble. Por un lado, que la labor de los altos cargos no sea lastrada por maniobras espurias; por otro, que los tribunales ordinarios no sufran presiones al juzgar a poderosos. La Constitución prevé que la figura proteja al presidente del Gobierno, ministros, diputados y senadores. Pero la Ley Orgánica del Poder Judicial amplió la categoría a los jueces y fiscales, a los magistrados del Tribunal Constitucional y del de Cuentas, vocales del Consejo General del Poder Judicial, miembros del Consejo de Estado, el Defensor del Pueblo y sus dos adjuntos. Y finalmente llegaron los Estatutos de autonomía para disparar la cifra con la inclusión de los miembros de los Gobiernos y Parlamentos autónomos y sus defensores del pueblo.

De nuevo, surge el interrogante de si todos somos iguales ante la ley:

\section{Artículo 14:}

"Los españoles son iguales ante la ley, sin que pueda prevalecer discriminación alguna por razón de nacimiento, raza, sexo, religión, opinión o cualquier otra condición o circunstancia personal o social".

El Consejo de Ministros ha aprobado en septiembre de 2018 su reforma del aforamiento, después de haber recibido la propuesta elaborada por el Consejo de Estado, que plantea modificar los artículos 71.3 y 102.1 de la Constitución para limitar el privilegio a los "delitos cometidos en el ejercicio de las funciones propias del cargo", una definición abierta e interpretable pero que apunta a los delitos de corrupción. Podemos ha anunciado su determinación de tramitar la reforma vía referéndum y que ésta afecte también a los miembros de la Casa Real.

\section{Débil separación de Poderes}

Primero el filósofo inglés J. Locke y, después, el francés Montesquieu, enunciaron el principio de separación de Poderes (Legislativo/Ejecutivo/Judicial) para, como decía Montesquieu, para que "el poder frene al poder" y evitar los peligros de una concentración de poder. Esta es una de las máximas, junto con el principio de soberanía nacional y principio de legalidad que se recogieron en la Declaración francesa del hombre y del ciudadano de 1789 y que después se han plasmado en las Constituciones democráticas. 
El "derecho de gracia", también conocido como indulto, es una renuncia al ejercicio del poder punitivo del Estado, fundada en razones de equidad, oportunidad o conveniencia pública (Política). El indulto es una causa de extinción de la responsabilidad penal, que supone el perdón de la pena. Es una situación diferente a la amnistía, que supone el perdón del delito, ya que por el indulto la persona sigue siendo culpable, pero se le ha perdonado el cumplimiento de la pena.

El indulto puede ser total o parcial. A su vez puede ser general y particular.

- El indulto total comprende la remisión de todas las penas a que hubiere sido condenado el reo y que aún no hubieren sido cumplidas.

- El indulto parcial supone la remisión de alguna o algunas de las penas impuestas o su conmutación por otras menos graves.

La Constitución española concede al Rey el derecho de gracia, sometido a la ley y prohíbe los indultos generales (según su artículo 62.i) (artículo $62 \mathrm{CE}$ : Funciones del Rey.)

\section{$\underline{\text { Artículo 62.i) }}$}

«Corresponde al Rey:... i) Ejercer el derecho de gracia con arreglo a la ley. Se prohíben los indultos generales.»

"El indulto es difícilmente reformable porque esa figura es un derecho de gracia que se da graciosamente". "El problema surge cuando no es un derecho de gracia sino que se usa para dar privilegios a determinadas personas. Eso es muy grave y vulnera un principio básico del Estado de derecho". ${ }^{22}$

Resulta necesario, si no la supresión, sí al menos una reforma de la antiquísima (data de 1870) ley de indulto. Por lo menos, los decretos del Ejecutivo que dejan sin efecto resoluciones judiciales deberían "explicar por qué creen que esa persona merece el indulto", algo que ahora no ocurre. ${ }^{23}$

\section{Sistema electoral que nos aboca al chantaje nacionalista}

Nuestro sistema electoral parece haber sido diseñado para que a los grandes partidos nacionales les resulte muy difícil alcanzar la mayoría absoluta, y para que los partidos-bisagra que completan esas mayorías sean, no los partidos nacionales

\footnotetext{
${ }^{22}$ Por ejemplo, entre el 17 de febrero y el 29 de junio de 2012, el Ejecutivo indultó a 11 condenados de cuello blanco, todos ellos sujetos a penas de prisión. De los 11 indultados, seis -cuatro del PP y dos de CiU- fueron sentenciados por corrupción. Otros tres fueron condenados en 2010 por vender permisos falsos a inmigrantes.

${ }^{23}$ El magistrado de la Audiencia de Barcelona Santiago Vidal ha denunciado que el Gobierno conceda indultos sin ninguna motivación y que los beneficiados por la medida de gracia sean, en muchos casos, personajes públicos condenados en casos de corrupción. Vidal considera que el indulto es "una intromisión legal, pero ilegítima", del poder ejecutivo en el judicial. "Si Montesquieu levantase la cabeza..."."Cuando una persona es condenada con todas las garantías y luego esa condena es validada incluso por el Tribunal Supremo, no entiendo que el Consejo de Ministros conceda un indulto".
} 
más pequeños, sino partidos separatistas que se cobrarán sus servicios a un altísimo precio en el descoyuntamiento nacional.

\section{El art. 68.2, que establece que "la circunscripción electoral es la provincia".}

\section{Combinado con el $\underline{68.3}$, que ordena que el criterio de representación ha de ser} proporcional.

Nos ha deparado un sistema electoral que confiere a los partidos separatistas una alta capacidad de chantaje y bloqueo. El sistema de circunscripción provincial penaliza implacablemente a los partidos de ámbito nacional que tengan un porcentaje de voto inferior al $10 \%$ o $12 \%$, mientras respeta y hasta sobrerepresenta ligeramente a los partidos nacionalistas, triunfadores en sus provincias respectivas. Los partidos no mayoritarios de ámbito nacional son masacrados por el efecto combinado de la circunscripción provincial y la ley D'Hondt. ${ }^{24}$

\section{B. FORTALEZAS}

Afortunadamente, los elogios que se pueden realizar con respecto al texto constitucional son mayores que sus debilidades. ${ }^{25} \mathrm{Y}$ ello se refleja desde su Preámbulo ("La Nación española, en uso de su soberanía..." art.1.1.) hasta su articulado (La fuente última de las decisiones de los poderes públicos es el pueblo español (artículo 1.2: "La soberanía nacional reside en el pueblo español, del que emanan los poderes del Estado"; o bien, la dignidad de la persona, como centro y eje de los derechos fundamentales), algunos tan perseguidos en la fase preconstitucional como la libertad de expresión o la participación política. Aunque las fortalezas de nuestra Carta Magna son muchas, vamos a limitarnos a reseñar algunas de ellas.

\section{Principios, normas y valores en el texto constitucional}

Aunque presentes en las viejas Constituciones y también en textos normativos de rango legal, resulta innegable que en los últimos tiempos se asiste a una sobreabundancia en los propios textos constitucionales de disposiciones que expresan principios. Principios cuyo contenido se pretende que, dada la eficacia directa de la Constitución, irradie al resto del sistema jurídico. Así, los valores superiores de la Constitución (libertad, justicia, igualdad y pluralismo político) (Título Preliminar), junto a otros como la dignidad (art.10) y la seguridad, permiten una aplicación flexible por parte del Poder Judicial. El problema surge con respecto a ciertos conceptos jurídicos indeterminados tales como derecho a una vivienda

\footnotetext{
${ }^{24}$ El sistema d'Hondt es un método de promedio mayor para asignar escaños en sistemas de representación proporcional por listas electorales. Los métodos de promedio mayor se caracterizan por dividir a través de distintos divisores los totales de los votos obtenidos por los distintos partidos, produciéndose secuencias de cocientes decrecientes para cada partido y asignándose los escaños a los promedios más altos Por ejemplo, los resultados de las elecciones de 2011. El tercer partido en el cómputo nacional, Izquierda Unida, consiguió 11 diputados con un 6.9\% de los votos. El cuarto, UPyD, consiguió cinco diputados con un $4.7 \%$ de los votos. En cambio, CiU consiguió 16 diputados con un $4.2 \%$ de los votos; Amaiur, siete escaños con un $1.4 \%$ de los votos; el PNV, cinco con un $1.3 \%$; el BNG, dos con un $0.7 \%$. Redondeando, a UPyD le salió cada escaño cinco veces más caro en votos que a Amaiur, cuatro veces más caro que a $\mathrm{CiU}$

${ }^{25}$ Vid. El número monográfico dedicado al especial 40 aniversario de la Constitución española: El Notario del siglo XXI, Revista del Colegio Notarial de Madrid, n⿳802, noviembre-diciembre 2018.Disponible en: http://www.elnotario.es/.
} 
“digna y adecuada" (Artículo 47. Todos los españoles tienen derecho a disfrutar de una vivienda digna y adecuada).

\section{Título preliminar}

\section{Artículo 1}

1. España se constituye en un Estado social y democrático de Derecho, que propugna como valores superiores de su ordenamiento jurídico la libertad, la justicia, la igualdad y el pluralismo político.

2. La soberanía nacional reside en el pueblo español, del que emanan los poderes del Estado.

3. La forma política del Estado español es la Monarquía parlamentaria.

\section{Catálogo de Derechos fundamentales y de deberes}

Se han constitucionalizado tanto los deberes como los derechos.

Los deberes constitucionalizados fundamentales son el de defensa y el de tributación pero hay otros deberes contemplados en el texto constitucional. ${ }^{26}$

La Constitución española reconoce en su Título I, Capítulo II, un conjunto de derechos y libertades fundamentales que se corresponde con los modelos de las democracias occidentales avanzadas y que ocupan un lugar privilegiado. Estos derechos y libertades vinculan a todos los poderes públicos y, desde luego al legislador, que es el único poder habilitado constitucionalmente para regular su ejercicio dentro del respeto de su «contenido esencial» constitucionalmente declarado (artículo 53.1 CE).

\footnotetext{
26 Además del genérico deber de sometimiento a la Constitución, pueden encontrarse preceptos concretos en los que el texto constitucional se refiere a diversos deberes. Incluso la rúbrica del título I contiene este término, dentro de la expresión "De los derechos y deberes fundamentales". Asimismo, la sección $2^{\mathrm{a}}$ del capítulo II alude de nuevo a los deberes ("De los derechos y deberes de los ciudadanos"), a pesar de que el título del capítulo en el que está establecido se refiere sólo a "Derechos y libertades". En esta sección se encuentran referencias a deberes —o a lo que podría denominarse derechos-deberes_-, como el de defender a España (artículo 30.1), los deberes en casos de grave riesgo, catástrofe o calamidad pública (artículo 30.4), el deber de contribuir al sostenimiento de los gastos públicos (artículo 31.1, aunque no utiliza la palabra "deber", sino una expresión imperativa), los deberes de los cónyuges (artículo 32.2), o el deber de trabajar (artículo 35); sin embargo, en esta misma sección $2^{\mathrm{a}}$ hay otros artículos que no expresan deber alguno, sino sólo derechos (como los artículos 33, 34, 37 y 38), o incluso se refieren a otros aspectos (como el artículo 36, sobre el régimen de los colegios profesionales). Por otro lado, también hay otros deberes dispersos en el articulado de las restantes secciones y capítulos del título I: el deber de cursar la enseñanza básica (artículo 27.4, aunque no se utiliza el término "deber"), el deber de los padres de prestar asistencia de todo orden a los hijos (artículo 39.3), los deberes en relación con la salud pública (artículo 43.2), o el deber de conservar el medio ambiente (artículo 45.1). Además, hay otros deberes fuera del título I de la Constitución, como el deber de conocer el castellano (artículo 3.1, título Preliminar), la obligación de comparecer ante las comisiones de investigación de las cámaras parlamentarias (artículo 76.2, título III), o la de cumplir las sentencias y resoluciones judiciales firmes (artículo 118, título VI). Cfr. DÍAZ REVORIO, F. J., "Derechos humanos y deberes fundamentales. Sobre el concepto de deber constitucional y los deberes en la Constitución Española de 1978", Revista IUS, Año 5, nº 18, 2011, pp. 278-310.
} 
La práctica totalidad de estos derechos y libertades ha sido desarrollada legislativamente y el control de ese desarrollo y de su correcta aplicación e interpretación por los Jueces y Tribunales ha constituido una tarea esencial en la función jurisdiccional del Tribunal Constitucional, que ha garantizado el ámbito constitucionalmente protegido de los derechos fundamentales.

Para entender qué derechos y cómo se han incorporado a la Carta Magna, conviene hacer referencia a su distinta fundamentación: Para ello, vamos a referirnos a la "parábola del hombre topo" del Profesor A.E. Pérez Luño. ${ }^{27}$

Tras salir de su autoconfinamiento voluntario en los sótanos de una Institución cultural (desde la caída del régimen constitucional de la II República hasta la aprobación de la CE de 1978) se ve sorprendido ante algunos difíciles compromisos sobre los que gira cuestiones de nuestra Carta Magna:

-indisoluble unidad de la Nación española / reconocimiento del derecho a la autonomía de las nacionalidades y regiones

- democracia representativa y de partidos / democracia de participación popular directa

- garantía de libertad de empresa en el marco de una economía de mercado / subordinación al interés general de todo tipo de riqueza mediante la planificación económica

- compromiso de los poderes públicos para hacer reales y efectivas la libertad y la igualdad / relega los derechos económicos, sociales y culturales a meros "principios rectores de la política social y económica".

a) Fundamentación iusnaturalista (párroco): Reconocer esos derechos inviolables e inherentes al ser humano, que son superiores a las leyes positivas y al arbitrio de los gobiernos). "Se reconoce...".

\section{$\underline{\text { Artículo 21 }}$}

\section{Se reconoce el derecho de reunión pacífica y sin armas.}

\section{$\underline{\text { Artículo 22 }}$}

1. Se reconoce el derecho de asociación.

Artículo 28

2.Se reconoce el derecho a la huelga de los trabajadores para la defensa de sus intereses.

$\underline{\text { Artículo } 33}$

1. Se reconoce el derecho a la propiedad privada y a la herencia.

\section{$\underline{\text { Artículo 43 }}$}

${ }^{27}$ PÉREZ LUÑO, A. E., Los derechos fundamentales, 9a ed., Madrid, Tecnos, 2007. 


\section{Se reconoce el derecho a la protección de la salud.}

b) Fundamentación positivista (empresario): clave garantista: Constitución como instrumento jurídico para mantener y asegurar el statu quo económico y social. "Se garantiza..."

\section{Artículo 18}

1. Se garantiza el derecho al honor, a la intimidad personal y familiar y a la propia imagen.

3. Se garantiza el secreto de las comunicaciones y, en especial, de las postales, telegráficas y telefónicas, salvo resolución judicial.

\section{Artículo 27}

3. Los poderes públicos garantizan el derecho que asiste a los padres para que sus hijos reciban la formación religiosa y moral que esté de acuerdo con sus propias convicciones.

\section{Artículo 50}

Los poderes públicos garantizarán, mediante pensiones adecuadas y periódicamente actualizadas, la suficiencia económica a los ciudadanos durante la tercera edad. Asimismo, y con independencia de las obligaciones familiares, promoverán su bienestar mediante un sistema de servicios sociales que atenderán sus problemas específicos de salud, vivienda, cultura y ocio.

c) Fundamentación alternativa (abogado laboralista): los derechos fundamentales son mecanismos para promover e impulsar el ambicioso programa de transformaciones sociales, políticas y económicas. Se trata de promover una adecuación del estatuto de los derechos y libertades a los grandes objetivos transformadores constitucionales. "Promoverán...). Línea del "uso alternativo del Derecho".

\section{Artículo 9}

2. Corresponde a los poderes públicos promover las condiciones para que la libertad y la igualdad del individuo y de los grupos en que se integra sean reales y efectivas; remover los obstáculos que impidan o dificulten su plenitud y facilitar la participación de todos los ciudadanos en la vida política, económica, cultural y social.

Título I. De los derechos y deberes fundamentales

Capítulo tercero. De los principios rectores de la política social y económica

\section{Artículo 40}


1. Los poderes públicos promoverán las condiciones favorables para el progreso social y económico y para una distribución de la renta regional y personal más equitativa, en el marco de una política de estabilidad económica. De manera especial realizarán una política orientada al pleno empleo.

Estas diversas fundamentaciones ponen de relieve el resultado del consenso entre diversas fuerzas políticas que dio lugar a nuestra Carta Magna: desde el iusnaturalismo al positivismo y a fundamentaciones más progresistas). Como bien subraya el Profesor Pérez Luño, en su defensa de la Fundamentación del iusnaturalismo crítico, hay dos aspectos esenciales: a) unidad de sentido, mediante el respeto al principio de dignidad de la persona humana y mediante el respeto al contenido esencial de los derechos; b) pluralismo político, permitiendo debate social y participación de los ciudadanos a través de sus representantes en partidos políticos

Una de las dificultades con respecto al catálogo de derechos fundamentales estriba en la dificultad de que se ha dado diferente status a los derechos civiles y políticos con respecto a los derechos económicos, sociales y culturales. Mientras las garantías de los derechos civiles y políticos son asimilables a las de cualquier país de nuestro entorno, como límites a los poderes constituidos (frente a la arbitrariedad de la dictadura) no sucede lo mismo con los derechos sociales y económicos. Estos se encuentran recogidos en el Capítulo 3 del Título II de la Carta Magna bajo el título de "principios rectores" que, según el artículo 53, informarán la práctica legislativa, administrativa y judicial. En este último sentido, el Tribunal Constitucional los considera principios de optimización. Así, no suponen un criterio de inconstitucionalidad de leyes, ni recogen vínculos para el legislador presupuestario, ni pueden ser reclamados ante el poder judicial si sus mandatos son insatisfechos. ${ }^{28}$

Título I. De los derechos y deberes fundamentales

Capítulo cuarto. De las garantías de las libertades y derechos fundamentales

\section{$\underline{\text { Artículo 53 }}$}

1. Los derechos y libertades reconocidos en el Capítulo segundo del presente Título vinculan a todos los poderes públicos. Sólo por ley, que en todo caso deberá respetar su contenido esencial, podrá regularse el ejercicio de tales derechos y libertades, que se tutelarán de acuerdo con lo previsto en el artículo 161, 1, a).

${ }^{28}$ Las garantías de los derechos fundamentales (plenamente garantizados) son:

1) vinculación inmediata de los poderes públicos;

2) reserva de la potestad normativa en materia de Derechos fundamentales:

a) protección frente a la ley: respeto del contenido esencial y principio de reserva de Ley Orgánica

b) reforma constitucional;

3) Instrumentos jurisdiccionales para la protección de los Derechos fundamentales:

a) por la jurisdicción ordinaria: cláusula general de amparo judicial

b) por la jurisdicción constitucional en la tutela de los Derechos Fundamentales: recurso de amparo

4) El Defensor del Pueblo. 
2. Cualquier ciudadano podrá recabar la tutela de las libertades y derechos reconocidos en el artículo 14 y la Sección primera del Capítulo segundo ante los Tribunales ordinarios por un procedimiento basado en los principios de preferencia y sumariedad y, en su caso, a través del recurso de amparo ante el Tribunal Constitucional. Este último recurso será aplicable a la objeción de conciencia reconocida en el artículo 30.

3. El reconocimiento, el respeto y la protección de los principios reconocidos en el Capítulo tercero informarán la legislación positiva, la práctica judicial y la actuación de los poderes públicos. Sólo podrán ser alegados ante la Jurisdicción ordinaria de acuerdo con lo que dispongan las leyes que los desarrollen.

No es extraño que, con el advenimiento de la crisis económica de 2008, la satisfacción de estos preceptos se haya visto afectada, agravada por desequilibrios económicos, presupuestarios y financieros internos.

La reforma del art. $135 \mathrm{CE}$-a la que aludiremos más adelante- que vinculaba materialmente nuestra Constitución con los objetivos de estabilidad económica y sostenibilidad financiera de la Unión (mediante la LO 2/2012), tanto por el procedimiento como por el contenido, tuvo el efecto de quebrar el simbólico consenso constitucional. Esta reforma ha limitado las actuaciones en materia de política económica del nivel estatal, autonómico y local, con un control vertical reforzado, afectando a la autonomía económica, presupuestaria y fiscal del país respecto de la eurozona, y de las Comunidades autónomas respecto del Estado.

\section{REFLEXIONES FINALES: ¿Debe reformarse la Constitución?}

\section{Cláusulas constitucionales eternas o flexibles}

El tema de si se debe o no reformar una Constitución remite al enfrentamiento entre Constituciones flexibles y rígidas y al debate entre aquellos partidarios de la no revisión de los textos constitucionales, y aquéllos otros, inclinados por un revisionismo periódico. Se cuestiona la legitimidad de una Constitución en la medida en que las generaciones siguientes a su aprobación no han podido participar de la misma.

En relación a esta cuestión, se pueden diferenciar dos posiciones. La primera sería la sustentada por quienes defienden un compromiso constitucional a largo plazo. En esta línea se puede situar a Zagrevelsky cuando defiende la "Constitución viviente". Sostiene que la esencia de la Constitución es la propensión al futuro. Su posición es de defensa del compromiso constitucional a largo plazo.

Frente a esta posición se encuentra la del compromiso constitucional a corto plazo, que podría englobarse en la frase de que "la tierra pertenece a los vivos". Esta tesis fue la seguida en la Revolución francesa, cuando se afirmaba que una generación no tiene el derecho de someter a sus leyes a las generaciones futuras, y toda herencia en las funciones constitucionales es absurda y tiránica, por lo que sostenían que 20 años de vida de las Constituciones era lo adecuado.

El artículo 28 de la Constitución jacobina de 1793 de Francia establecía: 
"el pueblo de una nación siempre tiene el derecho de examinar, revisar o modificar su propia Constitución. Una generación no puede forzar a las siguientes a que estas sigan sus reglas más de 20 años. ${ }^{29}$

En esta misma línea de Constituciones para plazos cortos se sitúan algunos pensadores norteamericanos como Thomas Jefferson, tercer presidente de los EEUU y uno de los redactores de la Declaración de Independencia, de cuestionar la legitimidad de las leyes y defender el principio político del "consentimiento de los gobernados". Jefferson defendía una autonomía generacional que debía expresarse constitucionalmente. La soberanía generacional se plasmaba en Constituciones de vida breve -34 años- de manera que se permitiera a cada generación "reconstitucionalizarse". Cada generación se consideraba como una nación diferente con un derecho a tomar decisiones vinculantes pero sin poder obligar a las siguientes de la misma manera que tampoco se puede obligar a los habitantes de otros países.

Podría entenderse que nuestro texto constitucional no es verdaderamente democrático porque una parte de los ciudadanos españoles no pudieron participar en el referéndum celebrado en 1978 para su aprobación -bien porque no hubieran nacido o porque aún no habían llegado a la edad requerida para hacerlo-. Es decir, una buena parte de los ciudadanos españoles actuales no han tenido la posibilidad de aceptar o de rechazar la Carta Magna. Es un argumento que podría esgrimirse por parte de quienes consideren que las Constituciones deberían de tener una vigencia temporal limitada, de manera que las sucesivas generaciones de ciudadanos pudieran participar en aceptarla o no. La cuestión estriba si ha llegado el momento que sistemas liberales como la Constitución francesa del año I (1793), o la línea de Jefferson, deben ser aplicados y proceder a un relevo generacional de la Constitución.

\section{Constituciones en el tiempo: ¿conveniencia de mantener intactas o reformarlas?}

Las Constituciones nacen con una vocación de permanencia en el tiempo. Sin embargo, las fechas de aniversario de los textos constitucionales suelen servir de acicate para reflexionar y debatir sobre la trayectoria de la Carta Magna y poner de manifiesto algunos aspectos que, o bien convendría modificar o mejorar, o sino, incluir ex novo. La Constitución, pacto fundamental de convivencia democrática de una determinada generación, no puede ser insensible a los cambios sociales.

Se podrá argüir que las reformas constitucionales no son fáciles, que a veces equivale a abrir la "caja de Pandora" y, una vez iniciado un proceso de reforma, sea

\footnotetext{
${ }^{29}$ La idea de vinculación constitucional de futuro, de Constitución como un "precompromiso" del tipo de Ulises, que pide que le aten al mástil para evitar dejarse seducir por los cantos de sirenas y provocar que el barco se estrellara contra las rocas, es una metáfora frecuentemente utilizada para defender la rigidez constitucional y evitar que, las generaciones venideras puedan sucumbir a la tentación de modificar el texto constitucional. (ELSTER, J.; Ulysses and the Sirens: Studies: Studies in Rationality and Irrationality, Cambridge University Press, Cambridge, 1979). La defensa de un límite infranqueable de derechos fundamentales, para evitar alteraciones sustanciales, ha sido objeto de estudio por diversos iusfilósfos como Garzón Valdés y el "coto vedado" (Representación y democracia, 1989) o por Luigi Ferrajoli y la "esfera de lo indecidible" -siendo la indecibilidad absoluta excluyente de reforma constitucional-.
} 
difícil poner límites a las diversas opiniones que al respecto se puedan dar. ${ }^{30}$ Los cambios sociales y las mutaciones políticas - nacionales e internacionales- pueden hacer aconsejable introducir algunos cambios en la Carta Magna, ayudando a dar respuesta a nuevas necesidades -económicas, jurídicas o de otra índole que hayan ido surgiendo con el transcurrir del tiempo-. El respeto a los mecanismos de reforma que el texto constitucional establece junto a una imprescindible valoración de la oportunidad y pertinencia de introducir tales cambios no garantiza, sin embargo, que se llegue a un consenso.

El texto constitucional español cumple sus cuarenta años de vigencia y ya, desde hace algunos años, son varios los temas candentes que pugnan por hacerse un hueco a la hora de llevar a cabo una reforma constitucional, tal y como puso de manifiesto el Informe del Consejo de Estado, de 16 de febrero de 2006:

- el marco territorial de las Autonomías (Título VIII) y su sistema de financiación

- para asegurar la línea de integración en la Unión Europea

-u otros tales como supresión de la preferencia del varón en la sucesión a la Corona. ${ }^{31}$

La rigidez constitucional para llevar a cabo las reformas como la propia realidad política española ya nos hacen prever la gran dificultad que conllevaría una reforma constitucional. ${ }^{32}$ Por otro lado, otros temas que también se viene insistiendo en la necesidad de reformar, no tendrían que hacerlo necesariamente mediante la reforma constitucional -modificación o supresión del Senado, reforma de la ley electoral-, sino que legislativamente o reglamentariamente se podría llevar a cabo.

\footnotetext{
${ }^{30}$ No han faltado tampoco propuestas de revisión de la Constitución de otra índole, como la de la Ministra Carmen Calvo cuando, en julio de 2018, ha propuesta dotar a la Constitución de un lenguaje inclusivo con respecto al género femenino.

31 También algunas voces se alzan con la propuesta de un referéndum sobre Monarquía o República. La introducción del artículo $168 \mathrm{CE}$, que regula el denominado «procedimiento de reforma agravado», se debió al deseo de la mayoría conservadora de dar a la Corona una súper protección (a modo de «cláusula de intangibilidad» encubierta), para frenar las preferencias republicanas expresadas por los partidos políticos de izquierdas. A partir de finales del siglo XIX, todos los países europeos que expulsan a sus reyes no vuelven nunca a tener un sistema de monarquía (ni absolutista ni parlamentaria). Para garantizar este aspecto, incluyen esas "cláusulas de intangibilidad" que consisten en apartados que se incluyen en las Constituciones para impedir que determinados acuerdos de la Constitución puedan cambiarse en el futuro. Los primeros en incluir estas cláusulas fueron los franceses, en 1884, y en el siglo XX, les siguieron Portugal, Alemania e Italia. En las Constituciones de la historia constitucional española, nunca se ha incluido una cláusula de tal tenor, por lo que la monarquía ha sido restaurada más de una vez.

${ }^{32}$ Recordemos que la Constitución prevé un doble procedimiento de reforma, uno más rígido (art. $168 \mathrm{CE}$ ) y otro menos (art. $167 \mathrm{CE}$ ), diferenciándose en virtud de la materia que resulta afectada. Como bien advierte Martín-Retortillo Baquer con respecto a los alegatos irreflexivos que incitan a un aggiornamento de la Carta Magna, y a unas reformas de calado: "No basta cualquier ocurrencia de los irreflexivos ni las pretensiones utópicas de quienes apenas representan a nadie. Sin dejarse influenciar tampoco por el sinuoso proceder de quienes abominan del Estado democrático y social de Derecho. MARTÍN-RETORTILLO BAQUER, L.; "Reforma de la Constitución", Revista del Notario del siglo XXI, nº7, mayo-junio, Madrid, 2016, en <http://www.elnotario.es/index.php/hemeroteca/revista-67/6664-reformar-la-constitucion>.(última consulta realizada el 30 de julio de 2018). En esta misma línea de cautela con respecto a una posible reforma del texto constitucional se ha manifestado Blanco Valdés, advirtiendo que "La política de reforma constitucional no puede nunca plantearse como un ámbito para ganar apoyos electorales frente a las fuerzas cuyo voto sería necesario para que tal reforma se aprobase". BLANCO VALDÉS, R. L.; "La reforma constitucional en campo de Agramante", Revista del Notario del siglo XXI, n67, mayo-junio, Madrid, 2016, pp.38-42. (última consulta realizada el 31 de julio de 2018).
} 
La frustrada secesión de Cataluña en octubre de 2017 abrió una crisis en el sistema constitucional de 1978. A partir de ahí, han proliferado estudios y propuestas sobre la reforma de la Carta Magna. Un ejemplo puede encontrarse en la propuesta que presentaron, el 20 de noviembre de 2017, una decena de prestigiosos Catedráticos de Derecho Constitucional y de Derecho Administrativo bajo el título "Ideas para una reforma de la Constitución". ${ }^{33}$ En relación a la posibilidad de reformar la Constitución, los tres "padres" de la Constitución que siguen vivos, se pronunciaron en el seno de la Comisión de evaluación del sistema autonómico, del Congreso de los Diputados, el 10 de enero de 2018. Con todo, hay que advertir que se limitaron a la cuestión territorial (seguramente porque ese era el único cometido de la Comisión ante la que comparecían).

La Constitución se concibe como un texto inviolable tanto por parte del Estado como por parte de los ciudadanos. ¿Pero debería ser eternamente intocable?

En sus ya cuatro décadas de vida el texto constitucional fue sometido a reforma sólo en dos ocasiones, por exigencias de la Unión, en las que debía adecuarse el texto a la normativa europea.

a) La primera fue en 1992 y sirvió para adecuar la legislación al Tratado de Maastrich, permitiendo a los extranjeros residentes en España ser electores y elegibles en las elecciones municipales. Consistió en añadir el inciso "y pasivo" en el artículo 13.2.

Título I. De los derechos y deberes fundamentales

Capítulo primero. De los españoles y los extranjeros

\section{$\underline{\text { Artículo } 13}$}

1. Solamente los españoles serán titulares de los derechos reconocidos en el artículo 23, salvo lo que, atendiendo a criterios de reciprocidad, pueda establecerse por tratado o ley para el derecho de sufragio activo y pasivo en las elecciones municipales.

b) La segunda modificación tuvo lugar en 2011, con la reforma exprés del artículo 135, para priorizar la estabilidad presupuestaria ante el gasto social.

Artículo 135 vigente (desde septiembre de 2011)

1. Todas las Administraciones Públicas adecuarán sus actuaciones al principio de estabilidad presupuestaria.

2. El Estado y las Comunidades Autónomas no podrán incurrir en un déficit estructural que supere los márgenes establecidos, en su caso, por la Unión Europea para sus Estados Miembros.

\footnotetext{
33 <idpbarcelona.net/docs/actual/ideas_reforma_constitucion.pdf>. En relación a la posibilidad de reformar la Constitución, los tres "padres" de la Constitución que siguen vivos, se pronunciaron la Comisión de evaluación del sistema autonómico, del Congreso de los Diputados, el 10 de enero de 2018. Con todo, hay que advertir que se limitaron a la cuestión territorial (seguramente porque ese era el único cometido de la Comisión ante la que comparecían). SANTAOLALLA, F., ¿¿Hacia la reforma constitucional?”, El Notario del siglo XXI, nº 80, julioagosto 2018, en <http://www.elnotario.es/index.php/hemeroteca/revista-77/opinion/opinion/8386-hacia-lareforma-constitucional>. (última consulta realizada el 30 de julio de 2018).
} 
Una Ley Orgánica fijará el déficit estructural máximo permitido al Estado y a las Comunidades Autónomas, en relación con su producto interior bruto. Las Entidades Locales deberán presentar equilibrio presupuestario.

La actual situación económica y financiera no ha hecho sino reforzar la conveniencia de llevar el principio de referencia a nuestra Constitución

3. El Estado y las Comunidades Autónomas habrán de estar autorizados por Ley para emitir deuda pública o contraer crédito.

Los créditos para satisfacer los intereses y el capital de la deuda pública de las Administraciones se entenderán siempre incluidos en el estado de gastos de sus presupuestos y su pago gozará de prioridad absoluta. Estos créditos no podrán ser objeto de enmienda o modificación, mientras se ajusten a las condiciones de la Ley de emisión.

El volumen de deuda pública del conjunto de las Administraciones Públicas en relación al producto interior bruto del Estado no podrá superar el valor de referencia establecido en el Tratado de Funcionamiento de la Unión Europea.

4. Los límites de déficit estructural y de volumen de deuda pública sólo podrán superarse en caso de catástrofes naturales, recesión económica o situaciones de emergencia extraordinaria que escapen al control del Estado y perjudiquen considerablemente la situación financiera o la sostenibilidad económica o social del Estado, apreciadas por la mayoría absoluta de los miembros del Congreso de los Diputados.

5. Una Ley Orgánica desarrollará los principios a que se refiere este artículo, así como la participación, en los procedimientos respectivos, de los órganos de coordinación institucional entre las Administraciones Públicas en materia de política fiscal y financiera. En todo caso, regulará:

a) La distribución de los límites de déficit y de deuda entre las distintas Administraciones Públicas, los supuestos excepcionales de superación de los mismos y la forma y plazo de corrección de las desviaciones que sobre uno y otro pudieran producirse.

b) La metodología y el procedimiento para el cálculo del déficit estructural.

c) La responsabilidad de cada Administración Pública en caso de incumplimiento de los objetivos de estabilidad presupuestaria.

6. Las Comunidades Autónomas, de acuerdo con sus respectivos Estatutos y dentro de los límites a que se refiere este artículo, adoptarán las disposiciones que procedan para la aplicación efectiva del principio de estabilidad en sus normas y decisiones presupuestarias.

Escasos cambios que convierten a la Constitución Española de 1978 en la menos reformada de la UE, en comparación con otros países. Estos son algunos de los Estados miembro que más veces han modificado su Constitución en las últimas décadas: 
- Portugal: su constitución es del año 1976 y fue aprobada tras la Revolución de los Claveles. Ha sido modificada en 7 ocasiones, la última de ellas en 2005. Estos cambios han modificado aspectos ideológicos, de organización institucional y la regulación en materia económica y social.

- $\quad$ Francia: ha sido modificada en 24 ocasiones desde 1958. Cambios sobre el proceso de descolonización y de unidad europea, además de la creación de un Tribunal Penal o acerca de la igualdad entre hombres y mujeres, entre otros. La última de ella en 2008, fue para aumentar los poderes del Parlamento, al mismo tiempo que se reducían los del Presidente de la República y se incrementaban algunos derechos de los ciudadanos.

- $\quad$ Alemania: ha sufrido 60 modificaciones desde 1948.

- Austria promovió desde 1930 más de cien enmiendas y revisiones de distinto grado de su texto constitucional.

Uno de los principales inconvenientes para la reforma de la Constitución, es el difícil cumplimiento de los requisitos necesarios para poder llevarla a cabo. En España hay varias vías según se detalla en el Título X de la propia Constitución:

- $\quad$ El proyecto de reforma debe ser aprobado por los 3/5 del Congreso y del Senado. En el caso de no haber acuerdo entre ambas Cámaras, se intentará por medio de la creación de una Comisión de Composición paritaria del Congreso y Senado, presentando un texto que será votado por las dos Cámaras. Si no se aprueba con este procedimiento (siempre que el texto obtenga la mayoría del Senado) el Congreso por mayoría de $2 / 3$ podría aprobar una reforma constitucional.

- $\quad$ En el caso de que sea aprobado por las Cortes Generales debe someterse a referéndum, dentro de los 15 días siguientes a su aprobación, cuando así lo soliciten una décima parte de los miembros de cualquiera de las Cámaras.

Dicho proceso se lleva a cabo en el caso de que no se pretenda modificar totalmente o alguna disposición que afecte al Título preliminar, al Capítulo II, Sección Primera del Título I, o al Título II. Puesto que en tal caso, el procedimiento se agravaría. Por tratarse de cuestiones fundamentales.

Y así el 40 aniversario llega con la cuestión territorial abierta, con la monarquía en cuestión, con un protagonismo inesperado del Poder Judicial (Tribunal Supremo con la causa del referéndum catalán, el tema de las hipotecas) y con el estreno de un artículo diseñado para la excepción: el 155.

Título VIII. De la Organización Territorial del Estado

Capítulo tercero. De las Comunidades Autónomas

Artículo 155

1. Si una Comunidad Autónoma no cumpliere las obligaciones que la Constitución u otras leyes le impongan, o actuare de forma que atente 
gravemente al interés general de España, el Gobierno, previo requerimiento al Presidente de la Comunidad Autónoma y, en el caso de no ser atendido, con la aprobación por mayoría absoluta del Senado, podrá adoptar las medidas necesarias para obligar a aquélla al cumplimiento forzoso de dichas obligaciones o para la protección del mencionado interés general.

2. Para la ejecución de las medidas previstas en el apartado anterior, el Gobierno podrá dar instrucciones a todas las autoridades de las Comunidades Autónomas.

El texto constitucional reúne suficientes virtudes para merecer nuestro respeto, pero también suficientes defectos para no incurrir en lo que el profesor Luis Prieto Sanchís ha llamado "beatería constitucional" o lo que otros autores denominan "excesiva mitificación del texto". 34

En definitiva, una de las virtudes de la Constitución del 78 es ser fruto del consenso. Tiene elementos positivos y negativos. Unos que hay que conservar $y$, otros, fruto de la experiencia, habría que mejorar.

Positivos. Es el resultado de un pacto, que incluía desde el comunismo al fascismo. Ese marco ha dado lugar a un marco de democracia, libertad y ha permitido la alternancia política, bien sea con mayorías absolutas o minoritarias. Esto ha generado estabilidad.

Negativos. Hay otros elementos a considerar en una eventual reforma. La distribución territorial. En situaciones de crisis no se entiende que haya organismos paralelos. Se han producido unas transferencias (educación y sanidad, con un gastos muy altos) y que da problemas.

¿Qué eventuales reformas podrían abordarse? Es difícil una reforma global de la CE. Habría que dar pequeños pasos en la buena dirección:

- En la división de poderes. Justicia independiente, Legislativo que se encargue de elaborar leyes y controlar al Ejecutivo y no al revés.

- Mejorar las relaciones de los electores con los elegidos. No puede haber una ausencia de relación entre electores y elegidos.

- Buscar fórmulas de encaje territorial y recuperar competencias sobre educación y sanidad, para garantizar la igualdad entre todos los españoles. La mayoría de las propuestas de los expertos coinciden en simplificar los artículos dedicados al acceso a la autonomía en favor de una lista única de competencias estatales y de principios (residual, prevalencia, etc.), las características fundamentales de la financiación autonómica, y los mecanismos de participación horizontales y verticales.

\footnotetext{
${ }^{34}$ No tiene sentido encogerse de hombros ante un proceso reformista. Menos lógica tiene aún el argumento de que es preciso reformar la Constitución porque el $60 \%$ de los españoles no han votado la de 1978; ningún estadounidense vivo ha votado la suya, lo cual no ha impedido que haya sido enmendada 27 veces. Vid. PRIETO SANCHÍS, L., El constitucionalismo de los derechos: ensayos de filosofía jurídica, Madrid, Trotta, 2013.
} 
- Seguir impulsando una interpretación "evolutiva" de los derechos fundamentales. Ello hará posible que se pueda seguir avanzando no sólo en la igualdad real entre hombre y mujer (ya establecida en el texto constitucional) sino también en la igualdad real. En el mismo sentido, la protección y tutela de las personas con discapacidad, la protección de los niños y tantos otros que, fruto del resultado de los cambios sociales, resulta necesario para dar respuesta a las necesidades de esos sujetos de derecho.

En definitiva, en cuanto a la reforma de la Carta Magna es patente que, si en algún momento llega a materializarse en concretos proyectos reformadores, el poder de revisión constitucional ha de ejercerse con estricto atendimiento a los límites formales y procedimentales previstos al efecto (Título $\mathrm{X}$ de la Constitución), garantes en todo caso del consenso que expresan las mayorías políticas constitucionalmente exigidas para su aprobación.

A menudo no somos conscientes de la suerte que tenemos de vivir en un país democrático donde se respeta la libertad y la igualdad de las personas y menos, de que ello es consecuencia de nuestro texto constitucional. La democracia y la soberanía nacional son dos de los avances más importantes que hemos llevado a cabo en la historia y las Constituciones son un instrumento que ha marcado la vida de los pueblos. Conocer y respetar la Carta Magna, saber qué dice y cómo influye en nuestra vida forma parte de nuestra responsabilidad como ciudadanos. A la vez, nos hace más libres y nos permite ser más críticos ante el Estado y las decisiones de los políticos. Conocer nuestros derechos es imprescindible para poder defenderlos.

\section{REFERENCIAS BIBLIOGRÁFICAS}

AA.VV., Historia, nación y nacionalismo español, Madrid, Galaxia Gutenberg, Fundación Ortega y Gasset, 2013.

BLANCO VALDÉS, R. L., "La reforma constitucional en campo de Agramante", Revista del Notario del siglo XXI, nº67, mayo-junio, Madrid, 2016, pp.38-42. (última consulta realizada el 31 de julio de 2018).

CUENCA, A., "Informe. Una nueva reforma de la financiación autonómica" en Cuadernos Manuel Jiménez Abad, n¹3, Fundación Manuel Jiménez Abad de Estudios Parlamentarios y del Estado Autonómico, junio 2017, p.69. Disponible en: $<$ http://www.fundacionmgimenezabad.es/index.php?option=com_content\&view=cat egory\&layout=blog\&id=302\&Itemid=100916> .

DÍAZ REVORIO, F. J., "Derechos humanos y deberes fundamentales. Sobre el concepto de deber constitucional y los deberes en la Constitución Española de 1978", Revista IUS, Año 5, nº 18, 2011, pp. 278-310.

ELSTER, J,; Ulysses and the Sirens: Studies: Studies in Rationality and Irrationality, Cambridge University Press, Cambridge, 1979.

MARTÍN-RETORTILLO BAQUER, L.; "Reforma de la Constitución”, Revista del Notario del siglo XXI, $\mathrm{n}^{\circ} 67$, mayo-junio, Madrid, 2016, en $<$ http://www.elnotario.es/index.php/hemeroteca/revista-67/6664-reformar-laconstitucion>. (última consulta realizada el 30 de julio de 2018). 
PECES-BARBA, G., "La Constitución Española ayer y hoy”, Gabriel Cisneros Laborda, Miguel Herrero y Rodríguez de Miñón (Coordinadores) 20 años después: la constitución cara al siglo XXI, 1998, pp. 93-126.

PECES-BARBA, G., "25 años de la Constitución: entrevista a Gregorio PecesBarba Martínez". José Félix Tezanos Tortajada (entrev.), Temas para el debate, $\mathrm{N}^{\circ}$. 100 (marzo), 2003 (Ejemplar dedicado a: 25 años de la Constitución), pp. 21-32.

PECES-BARBA, G., "La reforma de la constitución", Claves de razón práctica, n 148, 2004, pp. 26-31.

PECES-BARBA, G., Las funciones de la Constitución”, en Alfonso de Julios Campuzano (Coordinador) Ciudadanía y derecho en la era de la globalización, Madrid, Dykinson, 2007, pp. 41-60.

PÉREZ LUÑO, A. E., Los derechos fundamentales, 9ª ed., Madrid, Tecnos, 2007.

PÉREZ ROYO, J., La Constitución explicada a mis nietas. Las claves para conocer nuestros derechos y ser más libres, Barcelona, Penguim Random House Grupo Editorial, 2018.

PRIETO SANCHÍS, L., El constitucionalismo de los derechos: ensayos de filosofía jurídica, Madrid, Trotta, 2013.

SANTAOLALLA, F. “¿Hacia la reforma constitucional?”, El Notario del siglo XXI, $\mathrm{n}^{\circ}$ 80, julio-agosto 2018, en <http://www.elnotario.es/index.php/hemeroteca/revista77/opinion/opinion/8386-hacia-la-reforma-constitucional>. (última consulta realizada el 30 de julio de 2018).

INFORMES, DIARIOS, WEB

"Financiación regional para competencias homogéneas e igual esfuerzo fiscal en 2013”. Fuente: <https://www.elblogsalmon.com/economia-domestica/el-cupovasco-es-realmente-injusto-con-el-resto-de-comunidades $>$.

Diario Público, 09.01.2019. https://www.publico.es/sociedad/violencia-generosupremo-sentencia-agresion-mutua-hombre-siempre-ejerce-violencia-machistamujer.html.

El Notario del siglo XXI, Revista del Colegio Notarial de Madrid, nº82, noviembrediciembre 2018.Disponible en: http://www.elnotario.es/.

CASTRO, C., “¿Es tan real como se dice la igualdad entre españoles?” Diario $L a$ Vanguardia, 17/09/2017. <https://www.lavanguardia.com/politica/20170917/431347759665/desigualdadeconomica-espana-comunidades-autonomas-pib-espanol-diferencias-financiacioninfraestructuras.html>.

Submetido em : 25/03/2019

Aceito em: 27/04/2019 